\title{
Transmantle focal cortical dysplasia in a patient with drug-resistant epilepsy
}

\author{
Varun Padmanaban (10,1' Jennifer Baccon, ${ }^{2,3}$ Jayant Acharya, ${ }_{1}^{4}$ Michael Sather ${ }^{1}$
}

${ }^{1}$ Department of Neurosurgery, Penn State Health Milton S. Hershey Medical Center, Hershey, Pennsylvania, USA 2Department of Pathology and Laboratory Medicine, Akron Children's Hospital, Akron, Ohio, USA

${ }^{3}$ Department of Pathology, Northeast Ohio Medical University, Rootstown, Ohio, USA

${ }^{4}$ Department of Neurology, Penn State Health Milton S. Hershey Medical Center, Hershey, Pennsylvania, USA

\section{Correspondence to} Dr Michael Sather; msather@pennstatehealth. psu.edu

Accepted 6 January 2022

Check for updates

C) BMJ Publishing Group Limited 2022. No commercial re-use. See rights and permissions. Published by BMJ.

To cite: Padmanaban $V_{\text {, }}$ Baccon J, Acharya J, et al. BMJ Case Rep 2022;15:e243983. doi:10.1136/bcr-2021-

243983

\section{DESCRIPTION}

Focal cortical dysplasia (FCD) is a malformation of cortical development and is a common cause of drug-resistant epilepsy in children and adults. ${ }^{1}$ We review images in a patient who was found to have FCD after suffering for years with drugresistant epilepsy. Her imaging and pathological findings were classic for FCD type IIb (transmantle dysplasia). Her case highlights the importance of a thorough workup by a multidisciplinary epilepsy surgery team with an epilepsy-specific MRI scan.

The patient is a middle-aged woman with medically resistant epilepsy. She began having seizures around the age of 3 . The semiology of her seizures includes rare generalised tonic clonic seizures with frequent night-time auras, which occasionally progress to complex partial seizures. She describes her auras as 'gasping for air' and a feeling that she cannot catch her breath. She had failed five antiepileptic agents, and prior to definitive surgical treatment, she was on two agents with moderate control. She also had a vagal nerve stimulator (VNS) placed with minimal improvement in her symptoms many years prior at an outside facility.

On referral to our epilepsy surgeon for replacement of her VNS generator, an epilepsy protocol MRI brain was performed. This revealed a classic 'transmantle sign' with fluid-attenuated inversion recovery (FLAIR) signal abnormality along the right frontal lobe extending to the ventricle, consistent with FCD (figure 1, arrow). She underwent

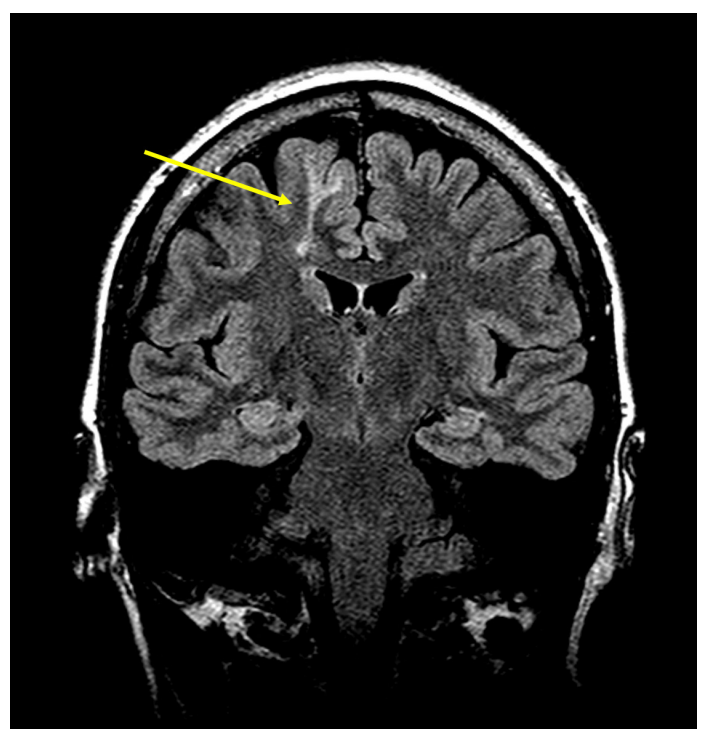

Figure 1 Coronal fluid-attenuated inversion recovery (FLAIR) sequence MRI showing transmantle dysplasia involving the right superior frontal gyrus.

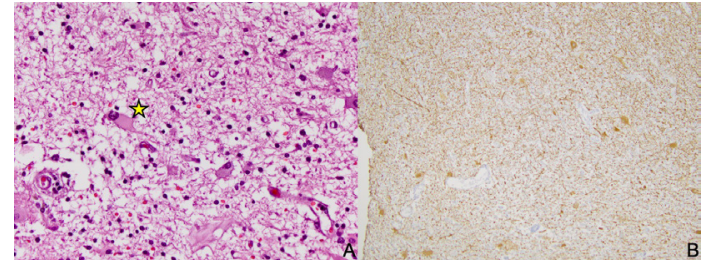

Figure 2 (A) H\&E section showing dysmorphic neurons (balloon cells, star) in background of cortical disorganisation. (B) Neurofilament immunohistochemical staining highlighting balloon cells.

a craniotomy with placement of subdural and depth electrodes for invasive seizure monitoring. Multiple stereotypical bilateral asymmetric tonic seizures were observed during sleep. Electroencephalography (EEG) findings were localised to the lesion seen on MRI. She underwent extended lesionectomy with motor mapping and maximal safe resection. Pathology noted cortical dysplasia type IIB with dysmorphic neurons on H\&E staining (figure $2 \mathrm{~A}$, star) and balloon cells seen with neurofilament protein (NFP) staining (figure 2B). Following surgery, she had a mild left-sided weakness which resolved by her first postoperative clinic visit. She has been seizure free for over 7 years with significant improvement in her quality of life and memory, and she has regained her driver's license.

The International League Against Epilepsy has published a clinicopathological classification system describing three subtypes of FCD. ${ }^{2}$ Typical FCD imaging findings include cortical thickening, blurring of the grey-white matter junction as well as T2 and FLAIR hyperintensity within the grey and/ or white matter. Type II FCD is the most common and homogenous type of FCD and is typically found within the frontal lobe often with a characteristic 'transmantle sign'. ${ }^{3}$ Advanced imaging, including epilepsy protocol MRI with a $3 \mathrm{~T}$ magnet, has significantly improved our ability to find FCD lesions. ${ }^{5}$ Treatment for FCD should include surgical evaluation with rates of seizure-freedom ranging from $62 \%$ to $90 \%{ }^{67}$

It is the responsibility of neurologists and neurosurgeons to critically evaluate and re-evaluate decisions in patients with epilepsy, including with placement or replacement of VNS. Epilepsyspecific MRI protocols such as the Harmonized Neuroimaging of Epilepsy Structural Sequences MRI protocol (HARNESS-MRI) are required for any patient with epilepsy and should be repeated if initial images are suboptimal or not available as in the case of this patient. ${ }^{89}$ 


\section{Patient's perspective}

I feel the epilepsy team helped me wonderfully. I was able to go back to school (and) got my graduate equivalency degree (GED). I was not able to do anything - I had very poor memory due to my seizures. I have five kids and it was tough on my husband as well. My kids were basically taking care of me. We came to the agreement of going through with the surgery and now I am totally seizure free. I never thought I would be able to go back to school but was able to get my GED.
Competing interests None declared.

Patient consent for publication Consent obtained directly from patient(s)

Provenance and peer review Not commissioned; externally peer reviewed.

Case reports provide a valuable learning resource for the scientific community and can indicate areas of interest for future research. They should not be used in isolation to guide treatment choices or public health policy.

\section{ORCID iD}

Varun Padmanaban http://orcid.org/0000-0002-9538-7708

\section{REFERENCES}

1 Guerrini R, Duchowny M, Jayakar P, et al. Diagnostic methods and treatment options for focal cortical dysplasia. Epilepsia 2015;56:1669-86.

2 Blümcke I, Thom M, Aronica E, et al. The clinicopathologic spectrum of focal cortical dysplasias: a consensus classification proposed by an AD hoc Task force of the ILAE diagnostic methods Commission. Epilepsia 2011;52:158-74.

3 Urbach H, Scheffler B, Heinrichsmeier T, et al. Focal cortical dysplasia of Taylor's balloon cell type: a clinicopathological entity with characteristic neuroimaging and histopathological features, and favorable postsurgical outcome. Epilepsia 2002;43:33-40.

4 Barkovich AJ, Kuzniecky RI, Bollen AW, et al. Focal transmantle dysplasia: a specific malformation of cortical development. Neurology 1997;49:1148-52.

5 Mellerio C, Labeyrie M-A, Chassoux F, et al. 3T MRI improves the detection of transmantle sign in type 2 focal cortical dysplasia. Epilepsia 2014;55:117-22

6 Hauptman JS, Mathern GW. Surgical treatment of epilepsy associated with cortical dysplasia: 2012 update. Epilepsia 2012;53 Suppl 4:98-104.

7 Chassoux F, Landré E, Mellerio C, et al. Type II focal cortical dysplasia: electroclinical phenotype and surgical outcome related to imaging. Epilepsia 2012;53:349-58.

8 Bernasconi A, Cendes F, Theodore WH, et al. Recommendations for the use of structural magnetic resonance imaging in the care of patients with epilepsy: a consensus report from the International League against epilepsy neuroimaging Task force. Epilepsia 2019;60:1054-68.

9 Wellmer J, Quesada CM, Rothe L, et al. Proposal for a magnetic resonance imaging protocol for the detection of epileptogenic lesions at early outpatient stages. Epilepsia 2013:54:1977-87.

Copyright 2022 BMJ Publishing Group. All rights reserved. For permission to reuse any of this content visit

https://www.bmj.com/company/products-services/rights-and-licensing/permissions/

BMJ Case Report Fellows may re-use this article for personal use and teaching without any further permission.

Become a Fellow of BMJ Case Reports today and you can:

- Submit as many cases as you like

- Enjoy fast sympathetic peer review and rapid publication of accepted articles

- Access all the published articles

Re-use any of the published material for personal use and teaching without further permission

Customer Service

If you have any further queries about your subscription, please contact our customer services team on +44 (0) 2071111105 or via email at support@bmj.com.

Visit casereports.bmj.com for more articles like this and to become a Fellow 